\title{
Classes of Drugs that Mitigate Radiation Syndromes
}

\author{
Ewa D. Micewicz ${ }^{1}$, Robert D. Damoiseaux ${ }^{2,3,4}$, Gang Deng ${ }^{5 \dagger}$, Adrian Gomez $^{6}$, \\ Keisuke S. Iwamoto ${ }^{1}$, Michael E. Jung ${ }^{5}$, Christine Nguyen ${ }^{1}$, Andrew J. Norris ${ }^{7}$, \\ Josephine A. Ratikan ${ }^{1}$, Piotr Ruchala ${ }^{6}$, James W. Sayre ${ }^{8}$, Dörthe Schaue ${ }^{1}$, \\ Julian P. Whitelegge ${ }^{6}$ and William H. McBride ${ }^{1 *}$
}

\begin{abstract}
${ }^{1}$ Department of Radiation Oncology, University of California at Los Angeles, Los Angeles, CA, United States, ${ }^{2}$ California NanoSystems Institute, University of California at Los Angeles, Los Angeles, CA, United States, ${ }^{3}$ Department of Molecular and Medical Pharmacology, University of California at Los Angeles, Los Angeles, CA, United States, ${ }^{4}$ Department of Bioengineering, Henry Samueli School of Engineering, University of California at Los Angeles, Los Angeles, CA, United States, ${ }^{5}$ Department of Chemistry and Biochemistry, University of California at Los Angeles, Los Angeles, CA, United States, ${ }^{6}$ Pasarow Mass

Spectrometry Laboratory, University of California at Los Angeles, Los Angeles, CA, United States, ${ }^{7} B C N$ Biosciences, LLC, Pasadena, CA, United States, ${ }^{8}$ Department of Biostatistics and Radiology, Fielding School of Public Health, University of California at Los Angeles, Los Angeles, CA, United States
\end{abstract}

Lifeng Kang,

The University of Sydney, Australia

Reviewed by:

Ikuo Kashiwakura,

Hirosaki University, Japan

Michael Abend,

Bundeswehr Institute of Radiobiology affiliated to the University Ulm,

Germany

*Correspondence:

William H. McBride

wmcbride@mednet.ucla.edu

${ }^{\dagger}$ Present address:

Gang Deng,

Shanghai Jiyu Pharmaceutical

Technology Co., Ltd., Shanghai, China

Specialty section:

This article was submitted to Experimental Pharmacology and Drug Discovery,

a section of the journal

Frontiers in Pharmacology

Received: 23 February 2021 Accepted: 27 April 2021

Published: 18 May 2021

Citation:

Micewicz ED, Damoiseaux RD, Deng G, Gomez A, Iwamoto KS, Jung $M E$, Nguyen $C$, Norris AJ,

Ratikan JA, Ruchala P, Sayre JW,

Schaue $D$, Whitelegge JP and McBride WH (2021) Classes of Drugs

that Mitigate Radiation Syndromes.

Front. Pharmacol. 12:666776.

doi: 10.3389/fphar.2021.666776
We previously reported several vignettes on types and classes of drugs able to mitigate acute and, in at least one case, late radiation syndromes in mice. Most of these had emerged from high throughput screening (HTS) of bioactive and chemical drug libraries using ionizing radiation-induced lymphocytic apoptosis as a readout. Here we report the full analysis of the HTS screen of libraries with 85,000 small molecule chemicals that identified 220 "hits." Most of these hits could be allocated by maximal common substructure analysis to one of 11 clusters each containing at least three active compounds. Further screening validated 23 compounds as being most active; 15 of these were cherry-picked based on drug availability and tested for their ability to mitigate acute hematopoietic radiation syndrome (H-ARS) in mice. Of these, five bore a 4nitrophenylsulfonamide motif while 4 had a quinoline scaffold. All but two of the 15 significantly $(p<0.05)$ mitigated H-ARS in mice. We had previously reported that the lead 4-(nitrophenylsulfonyl)-4-phenylpiperazine compound (NPSP512), was active in mitigating multiple acute and late radiation syndromes in mice of more than one sex and strain. Unfortunately, the formulation of this drug had to be changed for regulatory reasons and we report here on the synthesis and testing of active analogs of NPSP512 (QS1 and 52A1) that have increased solubility in water and in vivo bioavailability while retaining mitigator activity against $\mathrm{H}-\mathrm{ARS}(p<0.0001)$ and other radiation syndromes. The lead quinoline 057 was also active in multiple murine models of radiation damage. Taken together, HTS of a total of 150,000 bioactive or chemical substances, combined with maximal common substructure analysis has resulted in the discovery of diverse groups of compounds that can mitigate $\mathrm{H}$-ARS and at least some of which can mitigate multiple radiation syndromes when given starting $24 \mathrm{~h}$ after exposure. We discuss what is known about how these agents might work, and the importance of formulation and bioavailability.

Keywords: radiation mitigators, hematopoietic acute radiation syndrome, gastro-intestinal acute radiation syndrome, delayed effects of radiation exposure, multi-organ disease syndrome, High throughput screening 


\section{INTRODUCTION}

Historically, tissue damage after exposure to low density ionizing radiation (IR) such as X-rays and $\gamma$-rays was ascribed to cell death resulting in large part from the generation of short-lived free radicals and their destructive effects on DNA, events that were widely considered to be determined within minutes to hours after exposure. The finding by the Walter Reed Army Drug Development Program in the 1950s that thiol-based free radical scavengers, from which WR2721 (Amifostine) emerged as the lead compound, non-selectively radioprotect normal tissues if given close to the time of radiation exposure, support this contention (Murray and McBride, 1996). Unfortunately, such radioprotectors are far less effective if given after exposure, which is an essential requirement for radiation mitigation in the context of radiological accidents or terrorist action. Government agencies have outlined a general framework for the development of such mitigators in animal models; agents must be efficacious when administered at least $1 \mathrm{~d}$ after IR exposure by a route suitable for mass administration. Despite these tight restrictions, promising mitigators have emerged that are active against potentially lethal, acute radiation syndromes (ARS) in animal models that closely mimic the human situation (Bond et al., 1965; Kim et al., 2009; Burdelya et al., 2012; Medhora et al., 2012; Himburg et al., 2014; Jiang et al., 2014; Cohen et al., 2016; Micewicz et al., 2017; Steinman et al., 2018), and in many ways they challenge historical radiobiological concepts that DNA damage and repair, and rapid apoptosis, is essentially complete within $24 \mathrm{~h}$ since mitigation of radiation-induced syndromes only start at this time point.

ARS were first characterized in radiobiological studies performed largely in inbred mice shortly after WWII. As whole-body irradiation (WBI) doses were increased, the dose causing 50\% mortality (LD50) of mice plotted against mean/ median survival time (MST) was found to be discontinuous with mortality being expressed within several dose-time windows, each with a characteristic pathogenesis (Quastler, 1945a; Quastler, 1945b; Quastler, 1945c; Austin et al., 1956; Sacher and Grahn, 1964; Bond et al., 1965). Lethality in the lowest dose range occurs between 10 and $30 \mathrm{~d}$ and can generally be ascribed to hematopoietic failure (H-ARS). An increase in dose precipitates an earlier phase of mortality at around 5-9 d due to gastrointestinal damage (GI-ARS). H-ARS and GI-ARS are primarily due to depletion of highly proliferative stem/ progenitor compartments and failure of these tissues to maintain their functional compartment (Schaue and McBride, 2019; McBride and Schaue, 2020). The MST therefore reflects the tissue turnover time. A third, cerebrovascular/central nervous system syndrome (CVS/CNSARS) was identified 1-2 d after very high doses of WBI that is mechanistically different in being marked by brain edema, hemorrhage, and inflammation. Many variables may influence these morbidity and mortality patterns after WBI, including infection, immunosuppression, coincidental trauma, burns, and other exigent circumstances. In addition, individuals who survive ARS often develop delayed effects of acute radiation exposure (DEARE) that are largely associated with chronic inflammation and may display a multi-organ disease syndrome (MODS) with a shortened life span (Williams and McBride, 2011; Micewicz et al., 2019).

Although colony stimulating factors such as Neupogen (G-CSF), Neulasta (pegylated G-CSF), and Leukine (GMCSF) have been approved by the FDA for H-ARS mitigation in humans (Singh and Seed, 2020), their efficacy may be limited with respect to other ARS and DEARE syndromes (Farese et al., 2019). They may even exacerbate radiobiological damage in some tissues (van Os et al., 2000; Li et al., 2015). Since WBI causes multi-organ damage, mitigators should be agnostic with respect to tissue type, which might require that they act through shared highly conserved pathways. Rebalancing all damaged tissue systems might prevent a later downward spiral into MODS. Additional advantageous properties might be selectivity for radiation tissue damage without other normal tissue effects, and formulation in effective doses that are easily administered and not highly dependent on time and route of administration.

We have used high throughput screening (HTS) and structure-activity relationship (SAR) analyses to identify classes of novel mitigators with at least some of these attributes when tested in vivo (Micewicz et al., 2017). Remarkably, the HTS platform employed simple radiationinduced apoptotic death of a $\mathrm{CD}^{+} \mathrm{CD}^{+} \mathrm{T}$ lymphocyte line (Kim et al., 2009; Kim et al., 2011; Micewicz et al., 2017), suggesting that common core pathways are being targeted (Lant and Derry, 2014; Contreras et al., 2018).

We initially reported on results of a screen of 65,000 bioactive compounds that identified several classes of agents that could mitigate both radiation-induced lymphocyte apoptosis in vitro and $\mathrm{H}$-ARS in vivo. These included purine nucleosides and multiple tetracyclines and fluoroquinolones, but not other antibiotics (Kim et al., 2009; Kim and McBride, 2010). For the antibiotics, mitigation was unrelated to anti-microbial activity and SAR analysis identified them all as belonging to a class possessing a common ring structure. We then interrogated small chemical libraries of 85,000 compounds using the same screening platform and reported on a class of novel 4nitrophenylsulfonamide compounds (NPS), in particular piperazine derivatives (NPSP), with a lead compound NPSP512 that uniquely mitigated multiple ARS and late DEARE (Micewicz et al., 2017; Micewicz et al., 2019) including H-ARS, GI-ARS, radiation-induced pneumonitis and pulmonary fibrosis, neurological motor, sensory and memory deficits, and DEARE (Micewicz et al., 2017; Micewicz et al., 2019; Bhat et al., 2020; Duhachek-Muggy et al., 2020), as well as radioprotecting mice against H-ARS when given prior to WBI and displaying anti-tumor activity (Micewicz et al., 2017; Bhat et al., 2020; Duhachek-Muggy et al., 2020). Here, we describe other classes of mitigators from the HTS chemical screen and other sources. Over $20 \mathrm{H}$-ARS mitigators are described and their properties compared and discussed. We also describe the challenge in formulating the NPSP512 compound that led to analog synthesis designed to improve its pharmacological properties. 


\section{MATERIALS AND METHODS}

\section{HTS Assay}

The HTS assay has been described previously (Kim et al., 2009; Micewicz et al., 2017). In brief, TIL1 CD $4^{+} \mathrm{CD} 8^{+}$lymphocytic cells of $\mathrm{C} 3 \mathrm{H}$ murine lineage (McBride et al., 1992) were grown in MEM medium with $10 \%$ fetal calf serum and irradiated with 2 Gy. One hour later, 85,000 compounds were individually added from the ChemBridge DIVERSet (San Diego, CA, United States) or the Asinex (ASN) or Asinex Targeted (AST) libraries (Moscow, Russia). The AST library is configured around inhibitors of GPCRs (14 groups), kinases (six groups), ion channels (four ligand dependent groups), and proteases, while the others cover a broader pharmacophore space. Compounds were added at $10 \mu \mathrm{M}$ final concentration in $1 \%$ DMSO. Mitigation of radiation-induced apoptosis was assessed at $24 \mathrm{~h}$ by measuring ATP release (ATPlite, PerkinElmer, MA, United States). Based on the 99\% confidence limits compounds that increased viability to above $130 \%$ of the irradiated (diluent) controls (100\%) were retested over a range of concentrations using both ATPlite and Annexin/P.I. (Fisher, Carlsbad, CA, United States) for apoptosis. For in vivo assays, compounds were obtained from ChemBridge (San Diego, CA, United States) or synthesized in house (MJ, PR). Purity and stability were assessed by LC/MS and NMR. All chemicals were stored in $15 \mu \mathrm{L}$ DMSO or freshly suspended in $1 \mathrm{ml}$ of $2 \%$ Cremophor EL in water, and injected s. c. in the flank in $0.2 \mathrm{ml}$ volumes, unless otherwise stated. All control mice received the same diluent as the experimental groups. Other vehicle formulations are noted in the text. The HTS data are archived in The Collaborative Drug Discovery Vault (https:// app.collaborativedrug.com/vaults/425/searches/new) and freely available.

\section{Similarity and Substructure Analyses}

Data were compared for similarity and chemical features on a Collaborative Drug Discovery vault platform $\left(\mathrm{CDD}^{\mathrm{TM}}\right.$, Burlingame, CA, United States). The entire library was ranked by structural similarity to a referenced hit based upon the Tanimoto coefficient, excluding coefficients $<0.7$. Hits and non-hits within the library with similar structures were identified and maximal common substructure analysis performed to determine minimal core moieties (Chemaxon, Boston, MA, United States).

\section{In Vivo Testing}

$\mathrm{C} 3 \mathrm{Hf} / \mathrm{Sed} / / \mathrm{Kam}$ and $\mathrm{C} 57 \mathrm{Bl} / 6$ gnotobiotic male and female mice were bred at UCLA in our Radiation Oncology AAALACaccredited facility. Where indicated, Foxp $3^{\text {DTR/EGFP }}$ and $\mathrm{Nrf}^{-/-}$, both on the $\mathrm{C} 57 \mathrm{Bl} / 6$ background were used with the goal to monitor ARS under conditions of limited immune suppression and/or limited anti-oxidant defense, respectively. Foxp $3^{\text {DTR/EGFP }}$ transgenic mice (a gift from Dr Chatila) have the Diphtheria toxin receptor under the control of the Foxp3 promoter (a master regulator of regulatory $\mathrm{T}$ cells, i.e., Tregs) that allows the conditional depletion of Tregs upon exposure to Diphtheria toxin (DT). In order to deplete Tregs mice were i.p., injected with DT at $1 \mu \mathrm{g} /$ mouse (Sigma-Aldrich) every 3 days starting 2 days prior to WBI for a total of three injections while on maintenance antibiotics: Sulfatrim, $1 \mathrm{~g} / \mathrm{L}$ Kanamycin and $1 \mathrm{~g} / \mathrm{L}$ Ampicillin in drinking water (Haribhai et al., 2011). Nrf2 ${ }^{-l-}$ came from the Jackson Labs (Bar Harbor, ME, United States). All mice were housed at four per cage and randomized to experimental groups of $n=8$ at around 9-12 weeks of age, restricting the weight to match groups, e.g. males were 28-30 g when used. All IACUC-approved protocols and NIH guidelines were adhered to and defined criteria for premature humane euthanasia were strictly followed.

WBI was performed on unanesthetized and unrestrained mice using an AEC Gamma Cell 40 cesium irradiator (Cs-137) at a dose rate of around $60 \mathrm{cGy} / \mathrm{min}$ or a Gulmay Medical RS320 Irradiation System X-ray unit operated at $300 \mathrm{kV}$ (Gulmay Medical Ltd., Surrey, UK) with a permanent $4 \mathrm{~mm}$ Be filter and $1.5 \mathrm{~mm} \mathrm{Cu}$ and $3 \mathrm{~mm} \mathrm{Al}$ giving a $\mathrm{HVL}$ of $3 \mathrm{~mm} \mathrm{Cu}$. Institutional probit analyses were used to determine the dose that would cause lethality of $70 \%$ of mice within $30 \mathrm{~d}\left(\mathrm{LD}_{70 / 30}\right)$. Dosimetry used a Capintec ionization chamber calibrated to NIST standards and film (GAFCHROMIC EBT2, International Specialty Products, Wayne, NJ, United States) to check that deviations in the field uniformity is $<5 \%$. Partial body irradiations used $300 \mathrm{kV}$ X-rays (Gulmay, Surrey, UK) with anesthesia and Cerrobend $(1 \mathrm{~cm})$ to prevent exposure to unirradiated body parts. Mice were anaesthetized with an i.p. injection of $80 \mathrm{mg} / \mathrm{kg}$ Ketamine (Putney, NADA\#200-073) and $4 \mathrm{mg} / \mathrm{kg}$ Xylazine (AnaSed, NADA\# 139-236; Lloyd labs \#4811).

We have outlined the radiation syndromes our mice experience in considerable detail (Micewicz et al., 2017; Bhat et al., 2020; Duhachek-Muggy et al., 2020). In brief, H-ARS mortality occurred during the "classic" time frame between days 10-30 after exposure. Hematological damage is confirmed by Hemavet CBC observations made on blood from a separate group of identically treated mice so as not to influence survival data. To rule out infection as a cause of death, plasma is cultured for aerobes and anaerobes, which is facilitated by the use of gnotobiotic mice, which have a limited flora that does not change over the experimental period. Active mitigators allowed for CBC recovery around day 10-14, especially for lymphocytes and neutrophils. GI-ARS occurs 5-9 days after abdominal exposure and is accompanied by epithelial denudation that is prevented by mitigators. Lethality after lung irradiation in $\mathrm{C} 3 \mathrm{H}$ mice is due to pneumonitis and occurs 80-140 days after exposure, while C57Bl/6 mice present with fibrotic death after 150-200 days. We followed both lung pathologies by CT scans and all syndromes by histology.

\section{Chemical Synthesis of the NPSP512 Derivatives QS1 and 52A1}

QS1: The synthetic approach was adapted from Laval et al. (2009). $40 \mathrm{mmol}$ (6.49 g) of 1-phenylpiperazine was placed in a $250 \mathrm{ml}$ Erlenmeyer flask equipped with a magnetic stirrer. Subsequently, $45 \mathrm{ml}$ of anhydrous tetrahydrofuran (THF), $80 \mathrm{mmol}(8.8 \mathrm{ml})$ of 4-methylmorpholine and $50 \mathrm{ml}$ of anhydrous dimethyl sulfoxide (DMSO) were added, and the 
solution was cooled in an ice bath for $10 \mathrm{~min}$ with vigorous mixing. Then, $44 \mathrm{mmol}$ of appropriate sulfonyl chloride was dissolved in $25 \mathrm{ml}$ of anhydrous THF, and the resultant solution added in $2.5 \mathrm{ml}$ portions to the reaction mixture over a period of $10 \mathrm{~min}$ with mixing. The flask was covered and mixing continued overnight $(\sim 18 \mathrm{~h})$ after which the reaction mixture was transferred to a $500 \mathrm{ml}$ round-bottom flask, and the THF evaporated using a rotary evaporator (bath temp $35^{\circ} \mathrm{C}$ ). The remaining residue was diluted with water and formed precipitate was collected by filtration. Dried crude compounds were crystalized from either ethyl alcohol or acetonitrile giving corresponding compounds with overall yield of $72-98 \%$.

52A1 (4-(4-[2(aminomethyl)phenyl]piperazine1sulfonyl) phenyl)(hydroxy)oxoammonium): In brief, $3.73 \mathrm{~g}(10 \mathrm{mmol})$ of sulfonamide was placed in a $250 \mathrm{ml}$ one-neck round-bottom flask equipped with a magnetic stirrer. Subsequently, $100 \mathrm{ml}$ of anhydrous benzene, $2.97 \mathrm{ml}(10 \mathrm{mmol})$ of titanium (IV) isopropoxide $\left(\mathrm{Ti}(\mathrm{OiPr})_{4}\right)$, and $8.86 \mathrm{ml}(50 \mathrm{mmol})$ of $1,1,3,3$ tetramethyldisiloxane (TMDS) was added to a glass stopper capped bottle and all mixed for $24 \mathrm{~h}\left(60^{\circ} \mathrm{C}\right)$. The dark brown solution was then acidified with $4 \mathrm{~N} \mathrm{HCl}$ in 1,4-dioxane and evaporated on rotary evaporator. Crude compound was precipitated by addition of dry diethyl ether, separated by centrifugation, and dried under the vacuum. Subsequently, solid residue was extracted with hot water $(3 \times 50 \mathrm{ml})$, and combined extracts lyophilized, purified crystallization and a hydrochloride salt made. The formula weight was 377.44.

\section{Pharmacokinetic Analyses}

Pharmacokinetic data were obtained from blood plasma samples taken at indicated times after a single s.c., injection of NPSP mitigators at 5 or $10 \mathrm{mg} / \mathrm{kg}$ into $\mathrm{C} 3 \mathrm{H}$ male mice. Plasma samples $(20 \mu \mathrm{L})$ and an internal standard $(1 \mu \mathrm{L} ; \mathrm{F} 512,50 \mathrm{pmol})$ were added to methanol (79 $\mu \mathrm{L}$, Fisher Scientific Optima $\left.{ }^{\circledR} \mathrm{LC} / \mathrm{MS}\right)$ for a total volume of $100 \mu \mathrm{L}$, as well as $52 \mathrm{~A} 1$ standards $(1 \mu \mathrm{L}$ of 10,50 , $100,250 \mathrm{pmol}$ ) similarly prepared. These were vortexed for $2 \mathrm{~s}$ and centrifuged for $5 \mathrm{~min}$ at 16,000 rcf to obtain supernatants that were run on a $100 \times 2.1 \mathrm{~mm} \mathrm{C18} \mathrm{column} \mathrm{(Phenomenex} \mathrm{Kinetex)}$ using the 1290 Infinity LC system (Agilent 6460). The mobile phase was $0.1 \%$ formic acid in Milli-Q water, and $0.1 \%$ formic acid in acetonitrile. After elution, the NPSP was characterized on a triple quadrupole LC/MS system with an electrospray ionization source (Agilent 6460). Data acquisition was made in the positive ion mode for multiple reactions monitoring (MRM). The analyte signal was normalized to the internal standard and concentrations were determined by comparison to the calibration curves for plasma using linear regression analysis. PK values were obtained using SummitPk software to calculate Cmax and $\mathrm{T} 1 / 2$.

\section{Statistics}

Kaplan-Meier plots with log rank statistics were used to test for significant survival differences. Probit analyses were performed using SPSS v20 software and NCSS PASS 13 Power Analysis and Sample Size Software, Kaysville, Utah for power analysis. Analyses of variance were performed on all other data with a Brown-Forsythe test where homogeneity of variance assumptions were not met. Multiple comparisons procedures using Sidak were also performed. The Kruskal-Wallis non-parametric test was performed for some data distributions with less stringent assumptions. Significance was assessed at the 5\% level using SPSS v20 software (IBM SPSS Statistics, Armonk, NY, United States).

\section{RESULTS}

\section{In Vitro Screening}

Primary HTS of the chemical libraries identified 220 potential "hits" that enhanced lymphocytic cell survival to $>130 \%$ which was outside the $99 \%$ confidence limits of the control. Maximal common substructure analysis classified most of these hits to fall within 11 clusters, each with a common core pharmacophore and containing at least three active compounds (Figure 1-shaded). Secondary screening validated 23 compounds, of which 15 were cherry-picked for in vivo testing for mitigation of H-ARS in mice; the others being difficult to obtain. Four had a quinoline scaffold and came from the largest cluster (a total of 14 compounds at four levels of similarity). Five bore a 4-nitrophenylsulfonamide motif. All compounds had very little activity on non-irradiated cells suggesting some selectivity for radiation damage.

\section{In Vivo Screening}

$\mathrm{H}$-ARS was induced in $\mathrm{C} 3 \mathrm{H}$ or $\mathrm{C} 57 \mathrm{Bl} / 6$ male or female mice by WBI with $\mathrm{LD}_{70 / 30}$ doses estimated from institutional probit curves. Unless otherwise stated, all drugs were tested using the same schedule of five daily s. c. injections starting $1 \mathrm{~d}$ after $\mathrm{LD}_{70 / 30}$ doses of WBI, most at three different doses unless limited by availability. All 15 compounds shown in Figure 1 mitigated $\mathrm{H}$-ARS at at least one dose regimen without observed toxicity.

\section{4-(Nitrophenylsulfonyl)-4-Phenylpiperazine Compounds}

We previously reported on a novel and unique class of 4nitrophenylsulfonamide (NPS) H-ARS mitigators, four of which were 4-(nitrophenylsulfonyl)-4-phenylpiperazines (NPSP) (Micewicz et al., 2017). Lead NPS and NPSP compounds effectively mitigated $\mathrm{H}$-ARS in both strains of mice and both sexes. The lead NPSP compound 5355512 [a.k.a. 512 or \#5 (Bhat et al., 2019)] mitigated multiple radiation syndromes.

The shared nitrophenylsulphonamide moiety obviously is the active warhead for this class of drugs, but we chose a piperazine derivative as the lead compound because of its more favorable PK properties (Micewicz et al., 2017). We hypothesize that this enabled activity at $5 \mathrm{mg} / \mathrm{kg}$, which is easier to deliver to humans than the $75 \mathrm{mg} / \mathrm{kg}$ required for activity of simpler NPS compounds (Micewicz et al., 2017). In keeping with this hypothesis, analogs of NPSP512 that we synthesized without piperazine lost low dose (5 mg/kg) efficacy (Figure 2). Although the piperazine group could be modified with retained activity, not all NPSPs in our HTS dataset with $>70 \%$ similarity were active mitigators and this appeared to be due to 


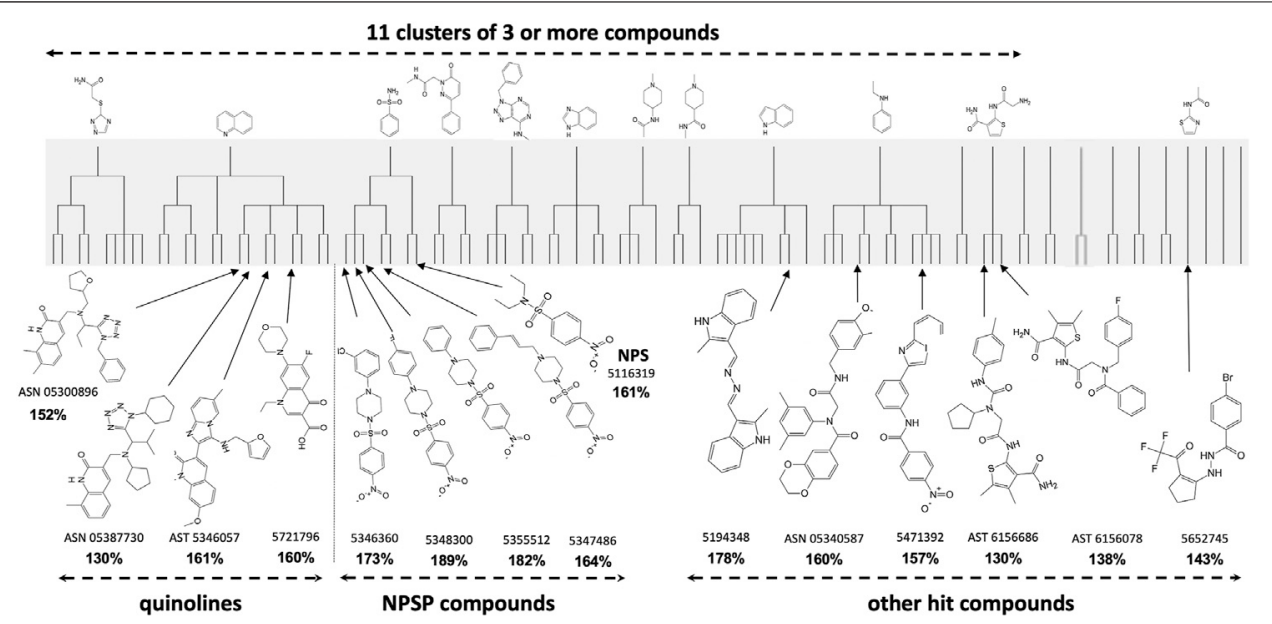

FIGURE 1 | Maximal Common Substructure analysis of in vitro HTS "hits" (shaded) showing clusters of at least three active compounds. The 15 validated hits cherry-picked for in vivo testing are shown along with the extent to which they mitigated 2 Gy in vitro radiation cytotoxicity (in bold) compared to controls treated with 2 Gy alone (100\%).

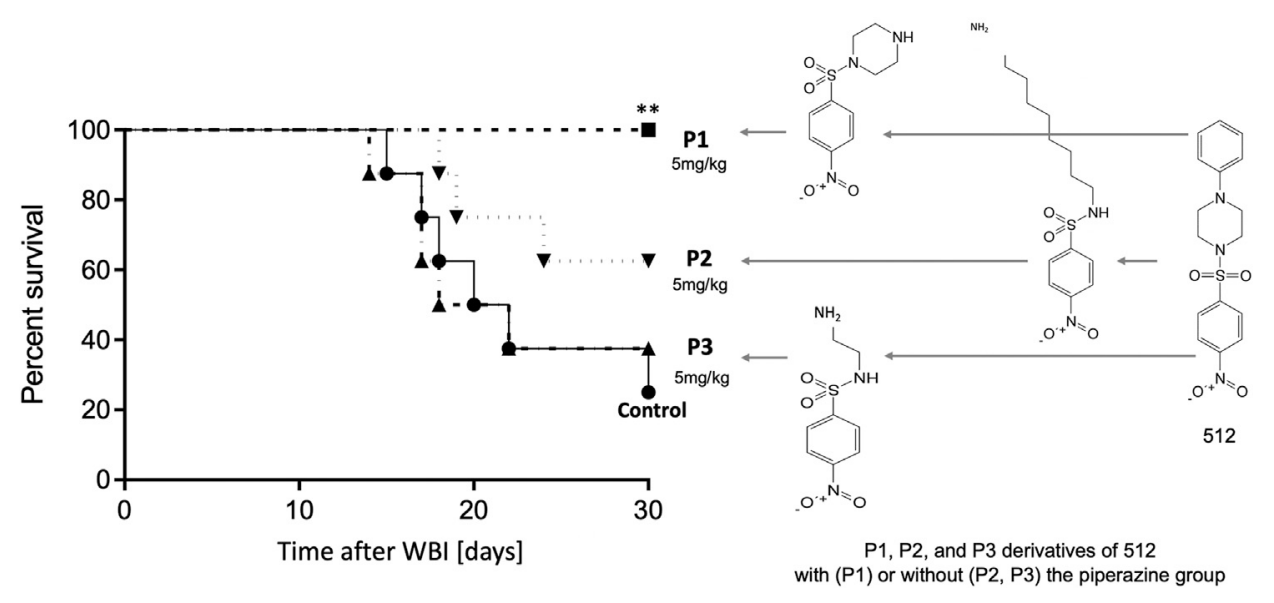

FIGURE 2 | The piperazine group is essential for efficacy of 512 at $5 \mathrm{mg} / \mathrm{kg}$, but can be modified without loss of activity, P1 being able to fully mitigate H-ARS $(p=0.0085)$ whereas P2 and P3 analogs without piperazine lost activity.

subtle chemical features associated with the piperazine group (Micewicz et al., 2017).

\section{Formulation, Quaternization, and Derivatization of 512}

For preliminary in vivo studies, drugs were dissolved in DMSO and formulated in Cremophor EL to minimize inter-drug differences in solubility. However, high concentrations of Cremophor have been reported to be associated with occasional hypersensitivity reactions in patients (Gelderblom et al., 2001), and the FDA now consider it an undesirable excipient. NPSP512 needed to be formulated for further advancement. Dozens of FDA-approved excipients were tested without much success. By analogy with x-ray crystallography of
N-(4-nitrophenyl)-N-phenylsulfonamide (Gomes et al., 1993), it seems that NPSPs can "stack" head to tail in alternate hydrophobic and hydrophilic layers to form large intermolecular complexes that "crash out" over time in aqueous solution. This was not a problem in our preliminary studies because solutions for injection were made fresh before use. Since we could find no excipient that could overcome this problem, we resorted to synthesis of chemically modified analogs. Guided by the extensive SAR studies, we knew that the groups attached to piperazine most likely affected solubility and chose this as the target for modification.

NPSP512 was quaternized as shown in Figure $\mathbf{3 A}$ and designated QS1. QS1 was 50 times more soluble in water than NPSP512 reaching $2.4 \mathrm{mg} / \mathrm{ml}$. Although not shown here, like the parent molecule, QS1 mitigated radiation-induced apoptosis and 
A

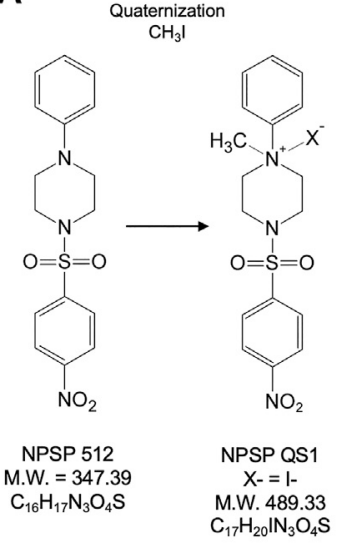

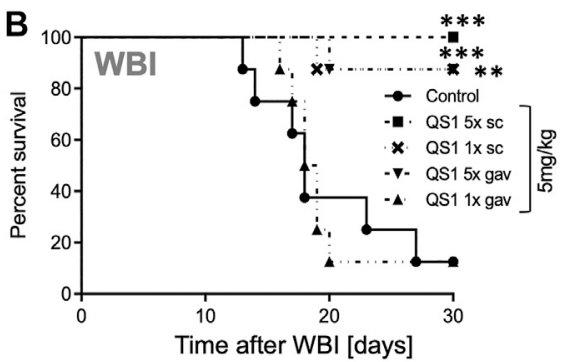

C

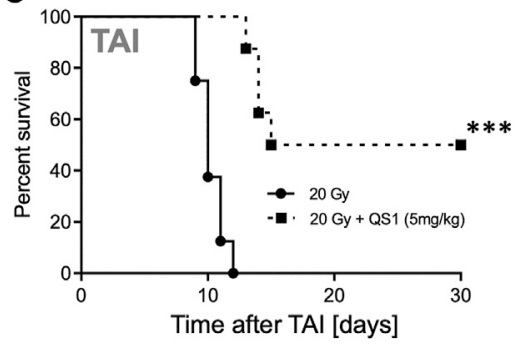

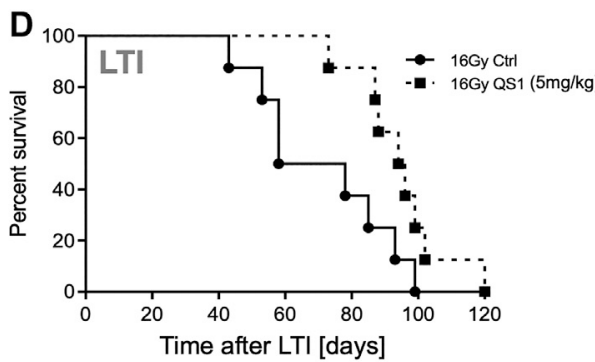

E

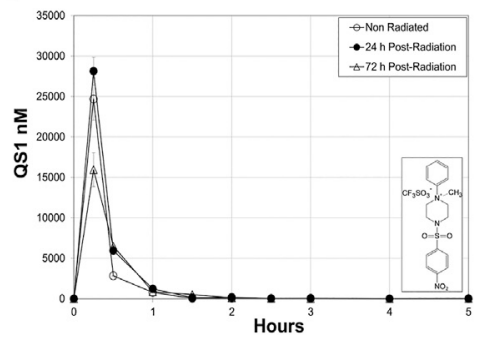

FIGURE 3 | (A) Quaternization of NPSP512 to yield QS1. (B) QS1 at $5 \mathrm{mg} / \mathrm{kg}$ mitigates H-ARS lethality in C3H male mice after LD70/30 WBI $(p<0.0001$; Cs source; 7.725 Gy) if given $5 \times$ daily by s.c., or gavage, or $1 \times$ if given s.c., $(p=0.0023)$, but not by gavage. (C) QS1 at 5 mg/kg, $5 X$ daily s.C., mitigates Gl-ARS after 20 Gy total abdominal irradiation in C57BL/6 male mice and (D) radiation pneumonitis in C3H mice after 16 Gy local thoracic irradiation. (E) PK parameters for $10 \mathrm{mg} / \mathrm{kg}$ QS1 injected s.c., assessed when drug is given 24 or $72 \mathrm{~h}$ after WBI showing a decrease in plasma concentration if given at $72 \mathrm{~h} .{ }^{*}=p<0.05,{ }^{* *} p<0.01,{ }^{* \star} p<0.001$.

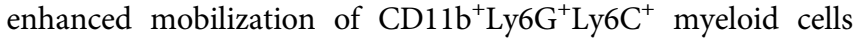
(Micewicz et al., 2017). The optimal dose of QS1 needed for mitigating $\mathrm{H}$-ARS lethality in $\mathrm{C} 3 \mathrm{H}$ mice was determined using 1 , 5,10 , or $20 \mathrm{mg} / \mathrm{kg}$ injected s. c., $5 \times$ daily starting $1 \mathrm{~d}$ after an $\mathrm{LD}_{70 /}$ ${ }_{30}$ WBI dose and found to be $5 \mathrm{mg} / \mathrm{kg}$ (not shown) -identical to that for the parent compound (Micewicz et al., 2017). In several different H-ARS experiments, $5 \mathrm{mg} / \mathrm{kg}$ s.c., (5x) increased survival from $30 \%$ to $90-100 \%$, a regime that was also effective for gavage delivery (Figure 3B). A single injection of QS1 $24 \mathrm{~h}$ after WBI was also effective if given s. c., but not by gavage. Like the parent 512 , the standard $5 \mathrm{~d}$ schedule of $5 \mathrm{mg} / \mathrm{kg} \mathrm{s}$. c. mitigated GI-ARS lethality in mice receiving $20 \mathrm{~Gy}$ to the abdomen (Figure 3C) and radiation pneumonitis after 16 Gy to the thorax (Figure 3D). PK studies (Figure 3E) showed that the $\mathrm{C}_{\max }$ for QS1 was almost 100-fold higher than for NPSP512 but that it had a very short half-life and could not be detected in plasma for longer than 3-4 $\mathrm{h}$ after injection, likely due to its metabolism. For comparison, the $\mathrm{C}_{\max }$ for NPSP512 occurs after $2 \mathrm{~h}$ and drug is detectable for up to $24 \mathrm{~h}$ (Micewicz et al., 2017). The PK characteristics were very similar in non-irradiated and WBI mice when drug was injected $24 \mathrm{~h}$ after WBI, but when injected $72 \mathrm{~h}$ post-WBI the $\mathrm{C}_{\max }$ was lower indicating radiation changes the plasma fluid volume over time.

Although QS1 solubility was improved 50 fold by quaternization, its bioavailability became suboptimal compared to the parent molecule. Over 90 derivatives of NPSP512 were therefore synthesized in attempts to optimize its pharmacology with respect to a) viable substituents for the $-\mathrm{NO}_{2}$ group, $\mathrm{b}$ ) solubility in water, and c) enhanced oral bioavailability using lipidation to improve intestinal absorption (Madsen et al., 2007; Bellmann-Sickert et al., 2011). All were screened for anti- apoptotic activity in vitro and seven of the most promising were tested for ability to mitigate H-ARS in vivo (Figure 4). The water-soluble 2-(aminomethyl)-derivative of NPSP512, $52 \mathrm{~A} 1$, emerged with greatly improved pharmacology while still being highly effective at mitigating lethality from $\mathrm{H}$-ARS in $\mathrm{C} 3 \mathrm{H}$ mice (Figure 4B). 52A1's ability to mitigate GI-ARS in C57Bl/6 mice was also robust albeit just below reaching statistical significance (Figure 4C, $p=0.09$ ) with the new FDApreferred GI-ARS model, which is WBI with one leg shielded (2.5\% bone marrow shielding) (Farese et al., 2019). Note that the MST for GI-ARS is delayed in gnotobiotic over more conventional mice (Wilson, 1963; Matsuzawa, 1965), and that $18.5 \mathrm{~Gy}$ is a high dose GI-ARS model that is not bone marrowdependent, unlike lower dose models (Mason et al., 1989). The PK of 52A1 was very similar to NPSP512, but with an almost 40fold higher $\mathrm{C}_{\max }$ (Figure 4D). Lipidation of NPSP512 yielded a water insoluble hydrophobic compound that was suspended in Kollipher for oral delivery. The length of the fatty acid chain is an important parameter for improving bioavailability (Madsen et al., 2007). Derivatives with chains of up to 20 -carbon fatty acids were synthesized and tested by the oral route (not shown). The 12carbon molecule, 52L12 was the most effective $(p<0.001$; Figure 4B).

\section{Quinoline Compounds}

The quinoline class detected by maximal common subclustering had four compounds that stood out after secondary screening. Their ability to inhibit radiation killing in vitro is shown in bold in Figure 1 and their ability to mitigate H-ARS is shown in Figure 5. Although drug availability and therefore dose response data was limited for three compounds, at least three of the four had 

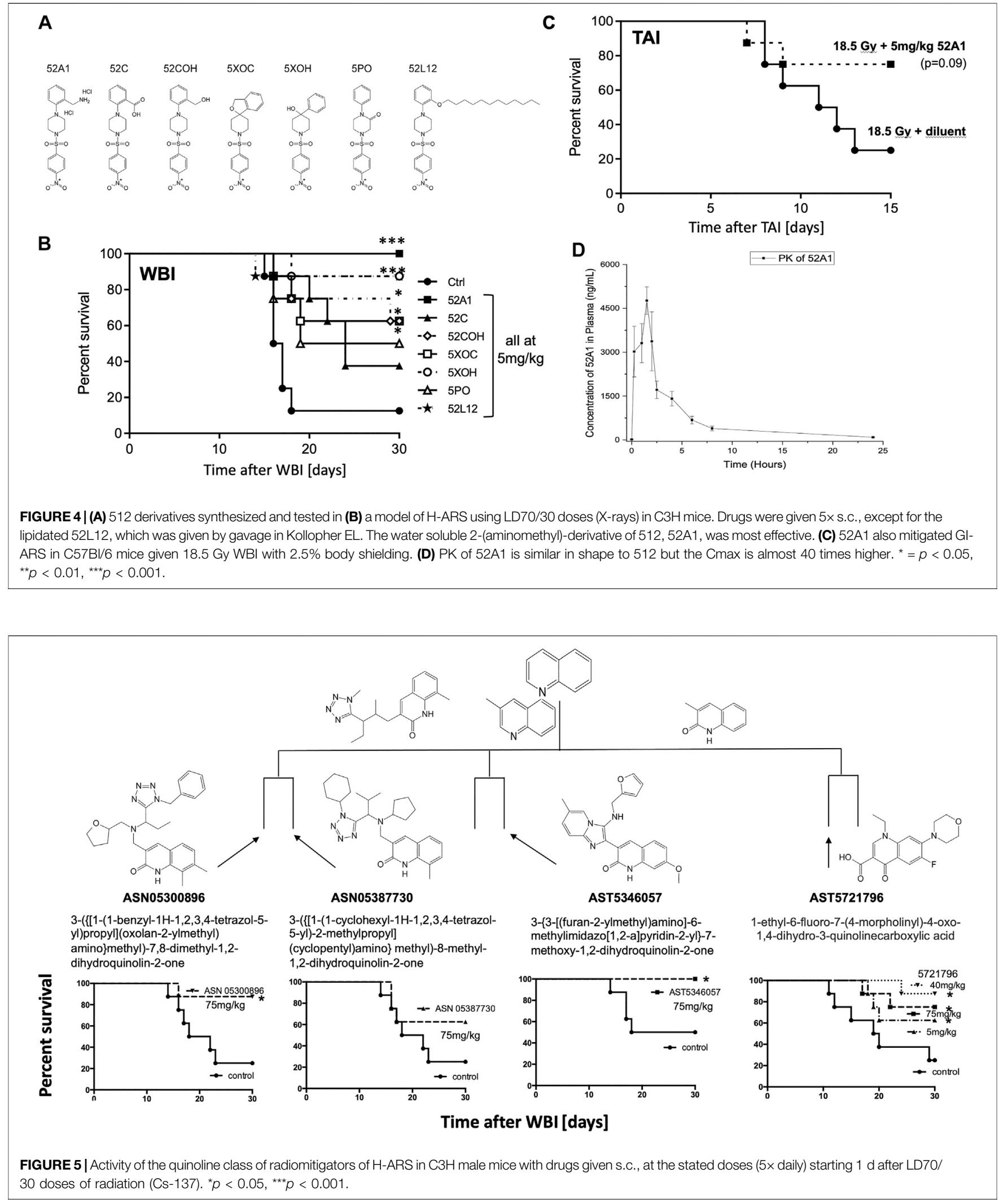


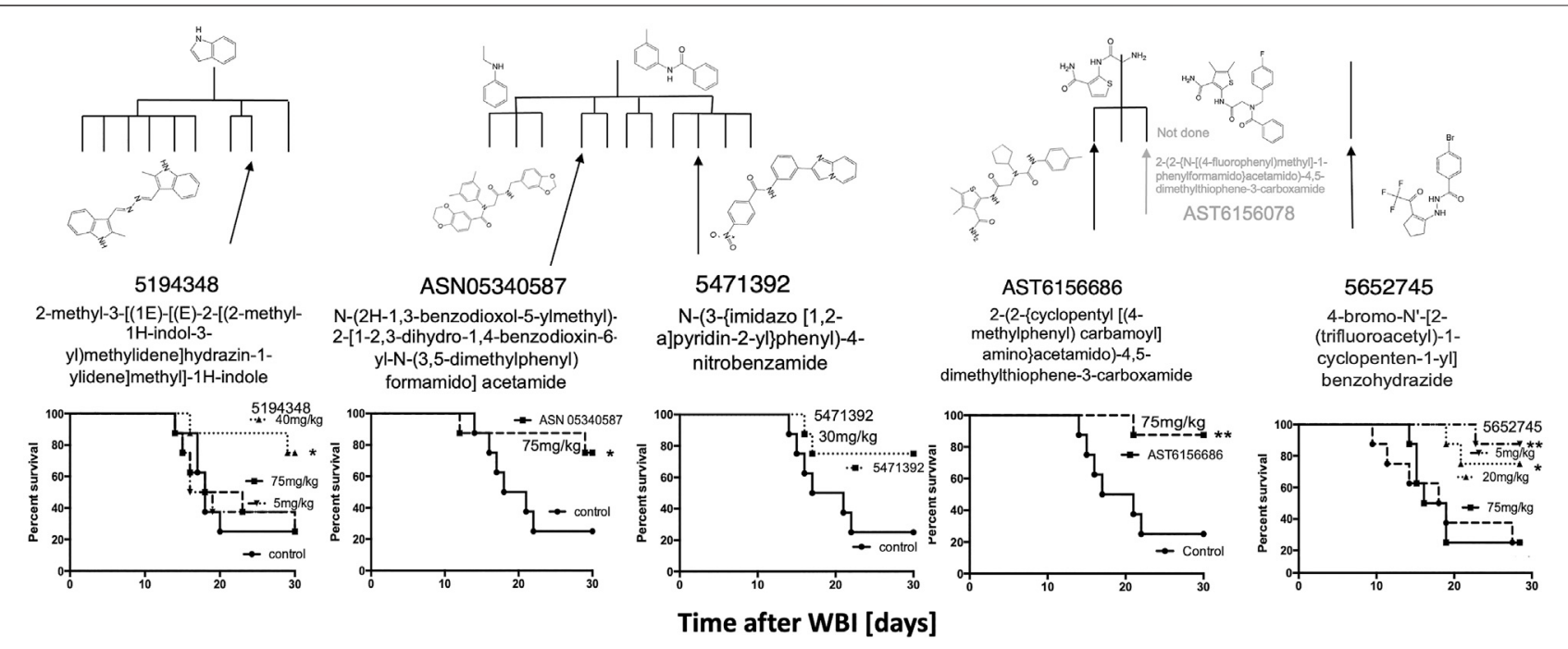

FIGURE 6 | Five other HTS in vitro "hits" mitigated H-ARS in C3H mice given once daily for 5 d starting 24 h after LD70/30 doses of WBI (Cs). * $p<0.05,{ }^{* *} p<0.01$, ${ }^{\star \star *} p<0.001$.

significant in vivo activity at $75 \mathrm{mg} / \mathrm{kg}$ and lower doses seemed less effective, where tested. One of the compounds in Figure 5, 5346057 (a.k.a. 057, BCN057, or YEL002), was of interest because it was identified as active in another HTS yeast screen, performed in parallel based on the DEL assay that measures mitigation of radiation cytotoxicity and genotoxity in the diploid yeast $S$. cerevisiae strain RS112 (Hafer et al., 2010; Kim et al., 2011) indicating that a conserved pathway is involved in mitigation. 057 had a dose modification factor for H-ARS of 1.15 when given s. c. in a daily 5 day course starting $24 \mathrm{~h}$ after WBI (Drs. Y. Revina, R. Schiestl pers. comm.). These drugs are very hydrophobic, which may be why high doses are needed for bioavailability. We had previously formulated 057 in $30 \%$ Captisol and shown that $90 \mathrm{mg} / \mathrm{kg}$ BCN057 given daily s.c., for $8 \mathrm{~d}$ starting on day +1 after 14,15 , and 16 Gy total abdominal irradiation mitigated GIARS in $\mathrm{C} 57 \mathrm{Bl} / 6$ mice by enhancing regeneration of Lgr5+ intestinal stem cells in vivo and in organoid culture (Bhanja et al., 2018). The same compound, as YEL002, also decreased ${ }^{(131)}$ I-induced DNA double strand breaks in thyroid cells (Hershman et al., 2011) and prevented radiation-induced carcinogenesis in mice (RS, pers. comm.). The lead quinoline therefore seems active in more than one model of radiation damage and this is likely true for the whole class given their structural similarity.

\section{Other HTS Compounds}

Since the two major groups of the most promising compounds in the HTS showed mitigator activity in vivo, "hit" compounds from the other groups $(n=6)$ with diverse structures shown in Figure 1 were also synthesized and tested for their ability to mitigate $\mathrm{H}$-ARS in vivo after LD70/30 radiation doses (Figure 6). Although studies were limited by compound availability to five of these, all had some mitigating ability, and all but one reached statistical significance.

To determine if compounds that were suboptimal during the initial in vitro screen (and below the potency of the 15 prime candidates), could still be active against H-ARS, we picked and tested four based on the fact that these four had increased in vitro cell survival to $135-145 \%$ and fell within the 122 compounds initially identified by HTS. The in vitro data are shown in bold in Figure 7. There was some efficacy, but only one was statistically significant and only at one concentration (Figure 7), which validated our selection process.

\section{Other Classes of Mitigators Purine Nucleosides}

We previously reported that the nucleoside adenosine, its derivative deoxyadenosine, and its analog vidarabine, which are $97 \%$ similar, were hits in our earlier bioactive HTS screen and showed some ability to mitigate H-ARS in mice (Kim et al., 2011). Nucleotides have a very short half-life in vivo but agonists and antagonists specific for one or more of the four known adenosine receptors, $\mathrm{A} 1, \mathrm{~A} 2 \mathrm{a}, \mathrm{A} 2 \mathrm{~b}$, and $\mathrm{A} 3$, have been generated with effects ranging from pro-to-anti-inflammatory and aidingto-limiting bone marrow recovery. We have investigated whether they might have better properties as H-ARS mitigators. . The A1 and A2 receptor agonist $5^{\prime}$-(N-ethylcarboxamido)adenosine (NECA) at $0.1 \mathrm{mg} / \mathrm{kg}$ s.c., $(5 \mathrm{x})$ in our standard H-ARS model increased survival of $\mathrm{C} 3 \mathrm{H}$ male mice after $8 \mathrm{~Gy}$ WBI from 0 to $50 \%$. The A2 agonist CGS 21680 at $2 \mathrm{mg} / \mathrm{kg}$ s. c. (5x) increased survival of $\mathrm{C} 57 \mathrm{Bl} / 6$ mice after $9 \mathrm{~Gy}$ WBI from 20 to $80 \%$ and of $\mathrm{C} 3 \mathrm{H}$ mice after $8 \mathrm{~Gy}$ WBI from 0 to $25 \%$ (not shown). However, the A3 agonist 2-Cl-IB-MECA, the A2 agonist CV1808 at $1 \mathrm{mg} / \mathrm{kg}$, and IB-MECA at $1 \mathrm{mg} / \mathrm{kg}$, were ineffective. Although these studies were limited, there was little evidence that these compounds were sufficiently superior to warrant further development as sole mitigators.

\section{Natural Disaccharides}

Natural disaccharides, in particular D-(+)-trehalose, have been shown to protect DNA, cells, and organisms against UVB 


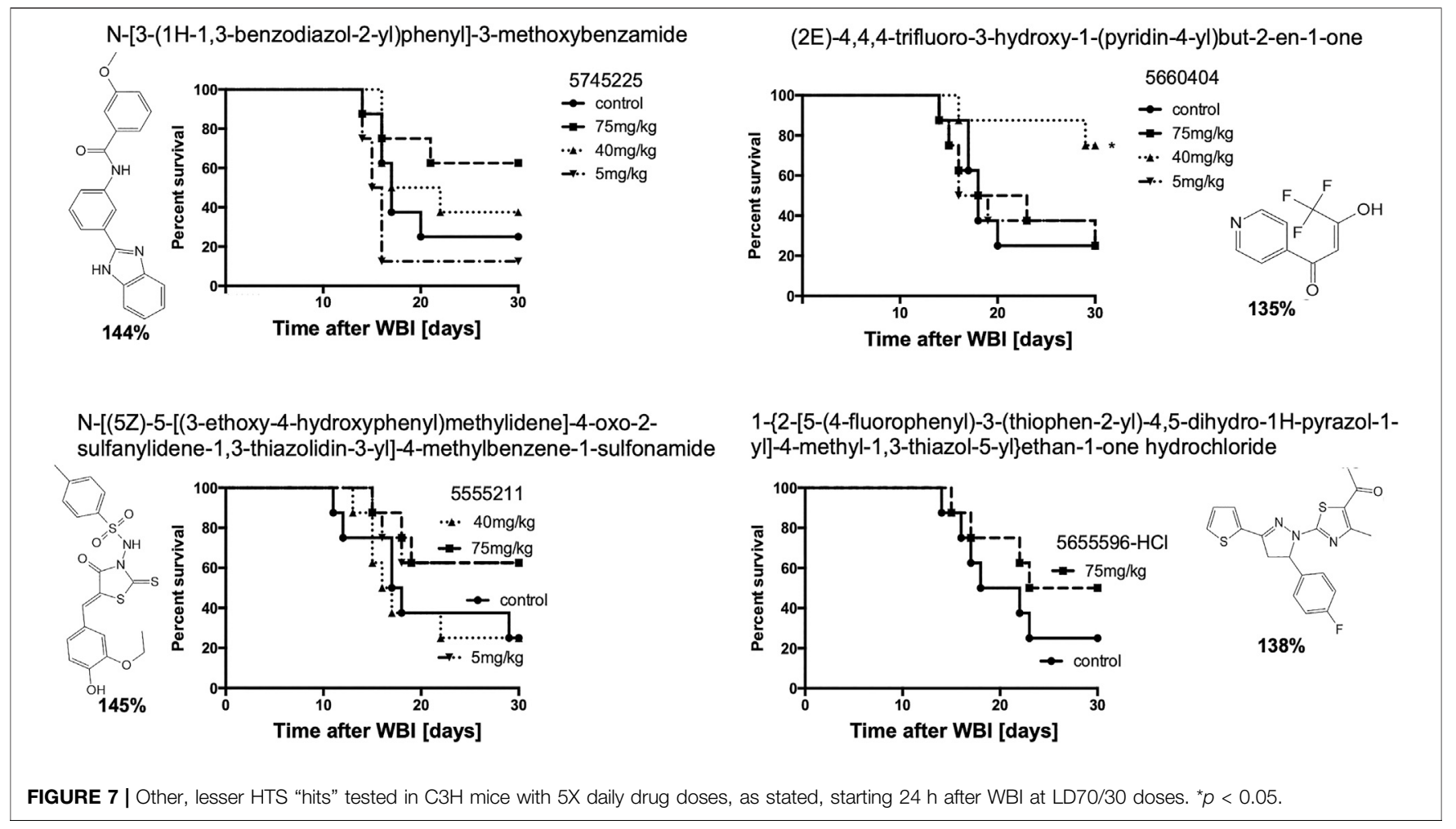

A<smiles>OCC1OC2OC3C(CO)OC(CO)C(O)C3OC2OC1O</smiles>

B

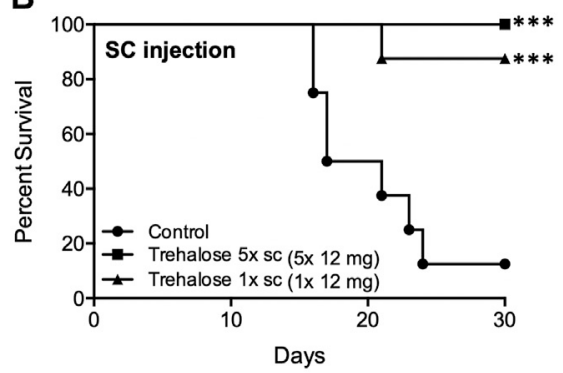

C

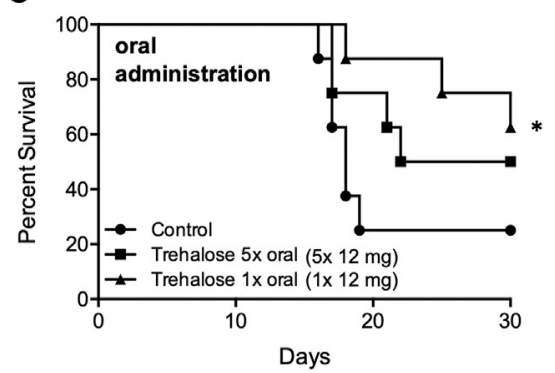

FIGURE 8 | Trehalose (A) and mitigation of radiation damage by (B) Trehalose (s.c., LD70/30), (C) Trehalose (oral, LD70/30). Each dose was 12 mg/animal in water. ${ }^{\star} p<0.05,{ }^{\star \star *} p<0.001$.

(Cejková et al., 2010; Cejková et al., 2012; Emanuele et al., 2014) and ionizing (Ledney et al., 1992; Yoshinaga et al., 1997; Webb and DiRuggiero, 2012; Liu et al., 2017; Paithankar et al., 2018) radiation damage, although few studies have been performed in mammalian systems. Trehalose is a multifunctional molecule that can act as an antioxidant (Elbein et al., 2003; Cejková et al., 2010) and anti-inflammatory agent (Ledney et al., 1992; Cejková et al.,
2011), reducing stress in multiple models. We had included it in excipient testing for NPSP512, only to find that alone it mitigated H-ARS lethality. Animal survival was increased by both single and five daily doses of $400 \mathrm{mg} / \mathrm{kg}$ trehalose/mouse administered $24 \mathrm{~h}$ after WBI by the s. c. route, and to a lesser extent orally (Figure 8). Comparison with several other saccharides (sucrose, raffinose, maltose, lactose) and carnosine, suggested that 
trehalose is superior at mitigation. Although the administered dose was high $(\sim 12 \mathrm{mg} /$ mouse), its solubility $(68.9 \mathrm{~g} / 100 \mathrm{~g}$ in $\mathrm{H}_{2} \mathrm{O}$ ) (Higashiyama, 2002), ready availability, high thermostability, and established lack of toxicity-it being a component of various pharmaceutical formulations and a frequent food additive-makes it a particularly intriguing candidate for clinical development.

\section{DISCUSSION}

We have used maximal common substructure analysis to classify 220 drugs capable of increasing lymphocytic survival in vitro $24 \mathrm{~h}$ after exposure to 2 Gy ionizing radiation. Remarkably, almost all of these could be attributed to 11 clusters of three or more compounds. Further screening to select for the most active compounds resulted in 15 drugs to test in vivo, and in spite of their diverse structures, almost all of these mitigated against $\mathrm{H}$-ARS in vivo. Five had a 4-nitrophenylsulfonamide (NPS) group in common that is likely the active moiety. Here we showed that a piperazine moiety in 4nitrophenylsulfonamidepiperazines (NPSP) improved the pharmacokinetics making the drug active at lower concentrations. Our lead NPSP, and all active agents in this class, act broadly by mitigating multiple acute and late radiation syndromes (Micewicz et al., 2017; Bhat et al., 2020; DuhachekMuggy et al., 2020) at doses convenient for human administration. This is important because all tissues suffer radiation damage after $\mathrm{WBI}$.

Unfortunately, these studies were performed with the drug formulated in Cremophor, which the FDA considers an undesirable excipient. The sulfonamide pharmacophore has been used as a drug since the 1930s and is a current component of well over 100 approved drugs with antibacterial, anti-cancer, anti-carbonic anhydrase, anti-diabetic, anti-protease, anti-inflammatory, and many other activities (Supuran, 2017); to which radiation mitigation can now be added. Given their popularity, the lack of literature on their solubility and lipophilicity, which are key parameters for drug development and utilization, is puzzling (Perlovich et al., 2014). Formulation attempts to find suitable excipients for NPSPs unexpectedly failed and can be explained by the tendency for these structures to "stack" and crash out of solution over time, but we were able to overcome these limitations by synthesizing alternative structures QS1 and 52A1 that retained their mitigation properties while having markedly improved water solubility and bioavailability.

Four of the 15 chemicals selected for further study were quinolines, which is another versatile scaffold for drug development forming a broad spectrum of drugs with antimicrobial, anti-inflammatory, anti-diabetic, anti-cancer, antimalarial, anti-kinase, and other activities (Hussaini, 2016). Three of the four quinolines are shown here to have significant activity as H-ARS mitigators. These compounds are even more hydrophobic than NPSP512 but the lead compound 057 could be formulated in Captisol ${ }^{\mathrm{TM}}$ and has been shown to also mitigate H-ARS (Bhanja et al., 2018) and other radiation-induced conditions (R. Schiestl, pers. comm.). Another 4 of the 15 selected compounds, which were of diverse structures, were also active against H-ARS, as was Trehalose, which we tested as a possible excipient rather than a mitigator.

This study raises the question as to why a $24 \mathrm{~h}$ HTS screen using apoptosis by lymphocytic cells after 2 Gy irradiation should yield multiple mitigators of $\mathrm{H}$-ARS that can be classified and grouped by common chemical moieties, and why at least some of these compounds can, additionally to being effective against hematopoietic death can also mitigate damage to epithelial structures in multiple tissues, where the critical cellular target for lethality is quite different. For H-ARS, in most species, damage to the myeloerythroid-restricted common progenitor cell compartment, and not the lymphocyte, is most likely to result in H-ARS, and transfer of these cells is sufficient to prevent $\mathrm{H}$-ARS, bridging the developmental gap until more pluripotential stem cells develop (Na Nakorn et al., 2002). The FDA-approved mitigator, G-CSF is thought to act against $\mathrm{H}$-ARS by acting as a survival and proliferative signal for this population (Williams et al., 1990), although it can also decrease reactive oxygen species (ROS) and prevent apoptosis through activating the anti-oxidant, anti-inflammatory Nrf2 pathway (Yamaguchi et al., 2020). For GI-ARS, Lgr $5^{+}$epithelial cells in the base of the crypt appear to be the weak link (Hua et al., 2012). In this case, a quiescent, Bmi1+ "reserve" stem cell population (Tian et al., 2011; Yan et al., 2012) may repopulate empty stem cell niches after injury, reprograming themselves as Lgr5 ${ }^{+}$cells (Tetteh et al., 2015; Wabik and Jones, 2015; Beumer and Clevers, 2016; Jones and Dempsey, 2016; Gehart and Clevers, 2019).

Our HTS discovery of multiple classes of ARS mitigators using radiation-induced cell death of lymphocytic cells as targets might implicate a role for apoptosis in ARS. However, mitigators are given $24 \mathrm{~h}$ after IR in vivo, when most rapid p53-dependent apoptosis is over. A second wave of radiation-induced, p53independent apoptosis does occur as do later waves of ROS production and inflammation and those are the much more likely mitigator targets (Schaue and McBride, 2010; Schaue et al., 2015). Pro-inflammatory cytokines are generated through radiation-activated NF- $\mathrm{KB}$ and MAPK pathways, the classic DSB-initiated DNA damage response, and nucleic acid sensing pathways downstream of micronuclei and cytoplasmic nucleic acids that are increased after IR (Maelfait et al., 2020). From an evolutionary perspective, inflammatory programs enacted in immune and non-immune cells aim to remove potential pathogens, but after WBI they come at a risk of exacerbating radiation damage.

This simple view must be tempered by the fact that prooxidant, pro-inflammatory milieus provoke an antiinflammatory antagonistic response, often involving the antioxidant Nrf2 pathway. Mechanistically it is still not entirely known how tissues transition to an anti-inflammatory state that can support cell proliferation and restore tissue function, but it is clear that healing is compromised by RT and that radiation disease evolves over time with cyclical changes in inflammatory/ anti-inflammatory pathways and in redox and metabolic status (Schaue et al., 2015). The contribution of Nrf2 can be judged by the fact that mice with the Nrf2 pathway deleted are about $15 \%$ 

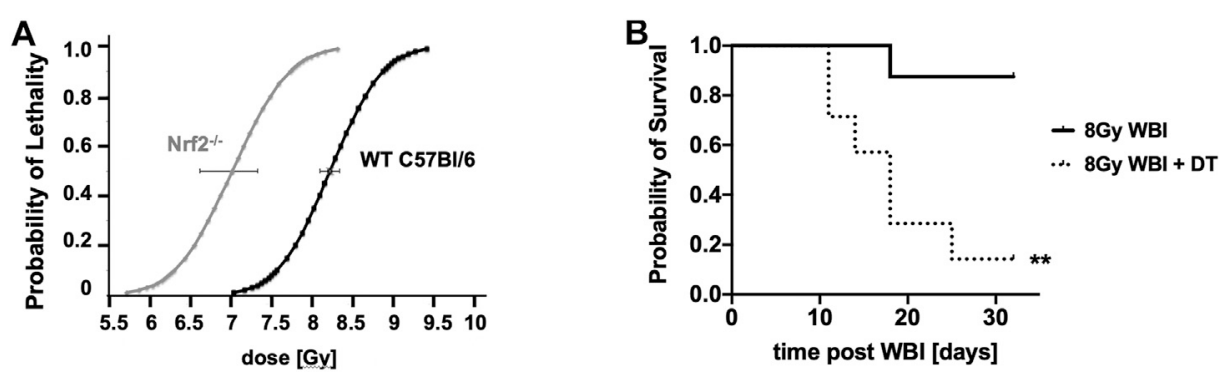

FIGURE 9 | The impact of Nrf2 depletion (A) and Treg depletion in Diphtheria toxin (DT)-treated Foxp3DTR/EGFP transgenic mice (B) $\left({ }^{\star \star} p=0.0037\right)$ on responses to $\mathrm{WBI}$ compared to aged-matched controls. ${ }^{\star \star} p<0.01$.

more radiosensitive to $\mathrm{WBI}$ than wild type $\mathrm{C} 57 \mathrm{Bl} / 6$ mice (Figure 9), which is in keeping with the finding that NRF2mediated Notch signaling improves hematopoietic stem/ progenitor function after IR (Kim et al., 2014). Similarly, depletion of anti-inflammatory Tregs increases the proinflammatory response to IR (Schaue et al., 2012) and radiosensitizes $\mathrm{C} 57 \mathrm{Bl} / 6$ mice to $\mathrm{WBI}$ (Figure 9). In fact, when studied, all of the mitigators mentioned in this paper, and others like G-CSF (Yamaguchi et al., 2020), quench radiation-induced inflammation and ROS production (Kim et al., 2009; Micewicz et al., 2017; Bhat et al., 2020) and it is reasonable to speculate that this is a requirement for effective mitigation. However, this is not the complete story, as can be seen from the other properties of the mitigator classes we discovered. Tissue recovery after injury engages many complex, interactive, highly conserved pathways within an entire responsive biological network which offers many possible points of intervention.

Both lead compounds from these two major classes of mitigators, the NPSPs and quinolones, where found to stimulate proliferation in stem cell organoid cultures of intestine, brain, lung and bone marrow (Micewicz et al., 2017; Bhanja et al., 2018; Bhat et al., 2019; Bhat et al., 2020; Duhachek-Muggy et al., 2020). This includes Lgr5+ stem cells present in steady state and during post-injury tissue regeneration in the intestinal crypts, and other tissues. The balance between self-renewal and differentiation in these stem/ progenitor cells is tightly controlled by a complex interplay of evolutionary conserved signaling pathways, including Wnt, Notch, bone morphogenetic protein, and Hedgehog (Clevers, 2019). Smoothened, a key component of the sonic hedgehog (SHH) signaling pathway is activated in the gut by NPSP 512 leading to nuclear translocation of the GLI1 transcriptional activator to mitigate GI-ARS (Duhachek-Muggy et al., 2020). Further, the quinoline 057 activates canonical Wnt- $\beta$-catenin signaling to mitigate GI-ARS (Bhanja et al., 2018) and extracellular vesicular delivery of Wnt rescues intestinal stem cells from radiation toxicity (Saha et al., 2016). It is reasonable to suggest that these agents may work through the same integrated signaling network. The $\mathrm{SHH}$ and Wnt signaling pathways are closely linked and, with Bmi-1, are involved in regulating embryonic and post-natal development, and stem cell proliferation (Ouspenskaia et al., 2016) to affect tissue repair and regeneration (Singh et al., 2018; Cao et al., 2020). We speculate that these developmental signaling pathways are reactivated in many tissues to promote tissue recovery and that mitigators can promote this process. Our colleagues (Himburg et al., 2017) have shown that, while IR activated canonical Wnt signaling, the Wnt antagonist Dickkopf-1 (Dkk1) mitigated H-ARS and promoted recovery of both long-term repopulating hematopoietic stem and progenitor cells, both directly and through niche interactions perhaps illustrating the complexity inherent in these pathways.

Others have reported that inhibition of the Wnt activator GSK-3 $\beta$ by SB21676324 mitigated H-ARS in C57Bl/ 6 male, but not female $\mathrm{C} 57 \mathrm{Bl} / 6$ or $\mathrm{C} 3 \mathrm{H}$ mice, indicating sex and strain differences (Daniel et al., 2020). The only sex difference we found was that NPSP512 stimulated neural progenitor populations in female, but not male mice (Bhat et al., 2020). Investigation of these pathways with a view to reconciling divergent results will need to take into account differences between tissues and sexes, comparison of varying radiation doses and administration schedules, and the degree of canonical activation of the Wnt pathway, which substantially impacts stem cell proliferation and differentiation (Luis et al., 2011). It is worth noting that Wnt signaling also provides crucial proliferative and survival signals to immature $\mathrm{T}$ cells (Ma et al., 2012), and our use of such cells for mitigator screening may have inadvertently biased our HTS towards agents that increase cell survival through activating these signaling pathways.

We suggest that the mitigators described here have, in addition to anti-inflammatory properties, the ability to enhance stem cell signaling through elements of the Hedgehog/Patch/Smoothened/Gli, BMP/TGF- $\beta$, FGF, WNT and Notch networks that govern embryogenesis, homeostasis and repair of adult tissues (Katoh and Katoh, 2006; Amankulor et al., 2009; Pitter et al., 2014; Caradu et al., 2018; Guo et al., 2018; Moparthi and Koch, 2019; Zhou et al., 2019). As far as mitigation of radiation damage is concerned, the enormous complexity inherent in these networks and the importance of context indicate a need for much further consideration as to mechanism. However, it should be pointed out that there is a 
close relationship between pathways controlling tissue repair and regeneration and inflammation, which may account for why these two aspects appear to be linked as common properties shared by classes of mitigators (Omenetti and Diehl, 2008; Amankulor et al., 2009; de la Roche et al., 2013; Braune et al., 2017; Shen et al., 2017; Caradu et al., 2018; Guo et al., 2018; Razumilava et al., 2018).

\section{DATA AVAILABILITY STATEMENT}

The original contributions presented in the study are included in the article/Supplementary Material, further inquiries can be directed to the corresponding author.

\section{ETHICS STATEMENT}

The animal study was reviewed and approved by the UCLA Animal Research Committee (ARC).

\section{REFERENCES}

Amankulor, N. M., Hambardzumyan, D., Pyonteck, S. M., Becher, O. J., Joyce, J. A., and Holland, E. C. (2009). Sonic Hedgehog Pathway Activation Is Induced by Acute Brain Injury and Regulated by Injury-Related Inflammation. J. Neurosci. 29, 10299-10308. doi:10.1523/jneurosci.2500-09.2009

Austin, M. K., Miller, M., and Quastler, H. (1956). Five- to Eight-Day Radiation Death in Mice. Radiat. Res. 5, 303-307. doi:10.2307/3570411

Bellmann-Sickert, K., Elling, C. E., Madsen, A. N., Little, P. B., Lundgren, K., Gerlach, L.-O., et al. (2011). Long-Acting Lipidated Analogue of Human Pancreatic Polypeptide is Slowly Released into Circulation. J. Med. Chem. 54, 2658-2667. doi:10.1021/jm101357e

Beumer, J., and Clevers, H. (2016). Regulation and Plasticity of Intestinal Stem Cells during Homeostasis and Regeneration. Development 143, 3639-3649. doi:10.1242/dev.133132

Bhanja, P., Norris, A., Gupta-Saraf, P., Hoover, A., and Saha, S. (2018). BCN057 Induces Intestinal Stem Cell Repair and Mitigates Radiation-Induced Intestinal Injury. Stem Cell Res. Ther. 9, 26. doi:10.1186/s13287-017-0763-3

Bhat, K., Duhachek-Muggy, S., Ramanathan, R., Saki, M., Alli, C., Medina, P., et al. (2019). 1-[(4-Nitrophenyl)sulfonyl]-4-phenylpiperazine Increases the Number of Peyer's Patch-Associated Regenerating Crypts in the Small Intestines After Radiation Injury. Radiother. Oncol. 132, 8-15. doi:10.1016/j.radonc.2018. 11.011

Bhat, K., Medina, P., He, L., Zhang, L., Saki, M., Ioannidis, A., et al. (2020). 1-[(4Nitrophenyl)sulfonyl]-4-phenylpiperazine Treatment After Brain Irradiation Preserves Cognitive Function in Mice. Neuro Oncol. 22, 1484-1494. doi:10. 1093/neuonc/noaa095

Bond, V. P., Fludner, T. M., and Archambeau, J. O. (1965). Mammalian Radiation Lethality. New York, NY: Academic Press.

Braune, J., Weyer, U., Matz-Soja, M., Hobusch, C., Kern, M., Kunath, A., et al. (2017). Hedgehog Signalling in Myeloid Cells Impacts on Body Weight, Adipose Tissue Inflammation and Glucose Metabolism. Diabetologia 60, 889-899. doi:10.1007/s00125-017-4223-5

Burdelya, L. G., Gleiberman, A. S., Toshkov, I., Aygun-Sunar, S., Bapardekar, M., Manderscheid-Kern, P., et al. (2012). Toll-Like Receptor 5 Agonist Protects Mice from Dermatitis and Oral Mucositis Caused by Local Radiation: Implications for Head-and-Neck Cancer Radiotherapy. Int. J. Radiat. Oncol. Biol. Phys. 83, 228-234. doi:10.1016/j.ijrobp.2011.05.055

Cao, H., Chen, X., Hou, J., Wang, C., Xiang, Z., Shen, Y., et al. (2020). The Shh/Gli Signaling Cascade Regulates Myofibroblastic Activation of Lung-Resident Mesenchymal Stem Cells via the Modulation of Wnt10a Expression during

\section{AUTHOR CONTRIBUTIONS}

Conceptualization: WM, MJ, and JW; Methodology: EM, RD, GD, AG, KI, MJ, CN, AN, JR, PR, and DS; Formal analysis: EM, $\mathrm{PR}$, JW, JS,WM, RD, and DS; Writing-original draft preparation: WM; Writing-review and editing: WM, and DS; Visualization: WM and DS; Supervision: WM, MJ, RD, KI, and JW; Funding acquisition: WW, JW, KI, AN, and DS. All authors have read and agreed to the published version of the manuscript.

\section{FUNDING}

This research was funded by the National Institutes of Health NIAID U19 AI067769 to the UCLA Center for Medical Countermeasures against Radiation (P.I. -WM.), HHSN272201500004C (NIH-NCI to WM and BCN), 1R43CA180316-01A1 (NIH-NIAID to WM and BCN), NIAID 2U19 AI67769 seed grant (P.I. -DS), 1R01CA226875 (P.I. -DS), and 1R01AI128739 (P.I. -KI).

Pulmonary Fibrogenesis. Lab. Invest. 100, 363-377. doi:10.1038/s41374-0190316-8

Caradu, C., Guy, A., James, C., Reynaud, A., Gadeau, A.-P., and Renault, M.-A. (2018). Endogenous Sonic Hedgehog Limits Inflammation and Angiogenesis in the Ischaemic Skeletal Muscle of Mice. Cardiovasc. Res. 114, 759-770. doi:10. 1093/cvr/cvy017

Cejková, J., Ardan, T., Cejka, C., and Luyckx, J. (2011). Favorable Effects of Trehalose on the Development of UVB-Mediated Antioxidant/Pro-Oxidant Imbalance in the Corneal Epithelium, Proinflammatory Cytokine and Matrix Metalloproteinase Induction, and Heat Shock Protein 70 Expression. Graefes Arch. Clin. Exp. Ophthalmol. 249, 1185-1194. doi:10.1007/s00417-011-1676-y

Cejková, J., Cejka, C., Ardan, T., Sirc, J., Michálek, J., and Luyckx, J. (2010). Reduced UVB-Induced Corneal Damage Caused by Reactive Oxygen and Nitrogen Species and Decreased Changes in Corneal Optics After Trehalose Treatment. Histol. Histopathol. 25, 1403-1416. doi:10.14670/HH-25.1403

Cejková, J., Cejka, C., and Luyckx, J. (2012). Trehalose Treatment Accelerates the Healing of UVB-Irradiated Corneas. Comparative Immunohistochemical Studies on Corneal Cryostat Sections and Corneal Impression Cytology. Histol. Histopathol. 27, 1029-1040. doi:10.14670/HH-27.1029

Clevers, H. C. (2019). Organoids: Avatars for Personalized Medicine. Keio J. Med. 68, 95. doi:10.2302/kjm.68-006-abst

Cohen, E. P., Fish, B. L., and Moulder, J. E. (2016). Clinically Relevant Doses of Enalapril Mitigate Multiple Organ Radiation Injury. Radiat. Res. 185, 313-318. doi:10.1667/rr4243.s1

Contreras, J. I., Robb, C. M., King, H. M., Baxter, J., Crawford, A. J., Kour, S., et al. (2018). Chemical Genetic Screens Identify Kinase Inhibitor Combinations that Target Anti-Apoptotic Proteins for Cancer Therapy. ACS Chem. Biol. 13, 1148-1152. doi:10.1021/acschembio.8b00077

Daniel, A. R., Lee, C. L., Oh, P., Luo, L., Ma, Y., and Kirsch, D. G. (2020). Inhibiting Glycogen Synthase Kinase-3 Mitigates the Hematopoietic Acute Radiation Syndrome in a Sex- and Strain- Dependent Manner in Mice. Health Phys. 119, 315-321. doi:10.1097/HP.0000000000001243

de la Roche, M., Ritter, A. T., Angus, K. L., Dinsmore, C., Earnshaw, C. H., Reiter, J. F., et al. (2013). Hedgehog Signaling Controls T Cell Killing at the Immunological Synapse. Science 342, 1247-1250. doi:10.1126/science.1244689

Duhachek-Muggy, S., Bhat, K., Medina, P., Cheng, F., He, L., Alli, C., et al. (2020). Radiation Mitigation of the Intestinal Acute Radiation Injury in Mice by 1-[(4Nitrophenyl)sulfonyl]-4-Phenylpiperazine. Stem Cells Transl. Med. 9, 106-119. doi:10.1002/sctm.19-0136

Elbein, A. D., Pan, Y. T., Pastuszak, I., and Carroll, D. (2003). New Insights on Trehalose: A Multifunctional Molecule. Glycobiology 13, 17R-27R. doi:10.1093/ glycob/cwg047 
Emanuele, E., Bertona, M., Sanchis-Gomar, F., Pareja-Galeano, H., and Lucia, A. (2014). Protective Effect of Trehalose-Loaded Liposomes against UVB-Induced Photodamage in Human Keratinocytes. Biomed. Rep. 2, 755-759. doi:10.3892/ br.2014.310

Farese, A. M., Bennett, A. W., Gibbs, A. M., Hankey, K. G., Prado, K., Jackson, W., 3rd, et al. (2019). Efficacy of Neulasta or Neupogen on H-ARS and GI-ARS Mortality and Hematopoietic Recovery in Nonhuman Primates After 10-Gy Irradiation With 2.5\% Bone Marrow Sparing. Health Phys. 116, 339-353. doi:10.1097/HP.0000000000000878

Gehart, H., and Clevers, H. (2019). Tales from the Crypt: New Insights into Intestinal Stem Cells. Nat. Rev. Gastroenterol. Hepatol. 16, 19-34. doi:10.1038/ s41575-018-0081-y

Gelderblom, H., Verweij, J., Nooter, K., Sparreboom, A., and Cremophor, E. L. (2001). Cremophor EL. Eur. J. Cancer 37, 1590-1598. doi:10.1016/s09598049(01)00171-x

Gomes, A. C., Biswas, G., Biswas, S., Biswas, G. K., Iitaka, Y., and Banerjee, A. (1993). Crystal Structure of N-(4-nitrophenyl)-N-phenylsulfonamide. J. Crystallogr. Spectroscopic Res. 23, 513-517. doi:10.1007/bf01182529

Guo, Y., Shi, G., Wan, H., and Zhou, M. (2018). Hedgehog Signaling Regulates the Expression Levels of Inflammatory Mediators in Cigarette-Induced Airway Inflammation. Mol. Med. Rep. 17, 8557-8563. doi:10.3892/mmr.2018.8861

Hafer, K., Rivina, Y., and Schiestl, R. H. (2010). Yeast DEL Assay Detects Protection against Radiation-Induced Cytotoxicity and Genotoxicity: Adaptation of a Microtiter Plate Version. Radiat. Res. 174, 719-726. doi:10.1667/rr2059.1

Haribhai, D., Williams, J. B., Jia, S., Nickerson, D., Schmitt, E. G., Edwards, B., et al. (2011). A Requisite Role for Induced Regulatory T Cells in Tolerance Based on Expanding Antigen Receptor Diversity. Immunity 35, 109-122. doi:10.1016/j. immuni.2011.03.029

Hershman, J. M., Okunyan, A., Rivina, Y., Cannon, S., and Hogen, V. (2011). Prevention of DNA Double-Strand Breaks Induced by Radioiodide-131I in FRTL-5 Thyroid Cells. Endocrinology 152, 1130-1135. doi:10.1210/en.20101163

Higashiyama, T. (2002). Novel Functions and Applications of Trehalose. Pure Appl. Chem. 74, 1263-1269. doi:10.1351/pac200274071263

Himburg, H. A., Doan, P. L., Quarmyne, M., Yan, X., Sasine, J., Zhao, L., et al. (2017). Dickkopf-1 Promotes Hematopoietic Regeneration via Direct and Niche-Mediated Mechanisms. Nat. Med. 23, 91-99. doi:10.1038/nm.4251

Himburg, H. A., Yan, X., Doan, P. L., Quarmyne, M., Micewicz, E., McBride, W., et al. (2014). Pleiotrophin Mediates Hematopoietic Regeneration via Activation of RAS. J. Clin. Invest. 124, 4753-4758. doi:10.1172/jci76838

Hua, G., Thin, T. H., Feldman, R., Haimovitz-Friedman, A., Clevers, H., Fuks, Z., et al. (2012). Crypt Base Columnar Stem Cells in Small Intestines of Mice are Radioresistant. Gastroenterology 143, 1266-1276. doi:10.1053/j.gastro.2012. 07.106

Hussaini, S. M. A. (2016). Therapeutic Significance of Quinolines: A Patent Review (2013-2015). Expert Opin. Ther. Patents 26, 1201-1221. doi:10.1080/13543776. 2016.1216545

Jiang, X., Engelbach, J. A., Yuan, L., Cates, J., Gao, F., Drzymala, R. E., et al. (2014). Anti-VEGF Antibodies Mitigate the Development of Radiation Necrosis in Mouse Brain. Clin. Cancer Res. 20, 2695-2702. doi:10.1158/1078-0432.ccr-131941

Jones, J. C., and Dempsey, P. J. (2016). Enterocyte Progenitors Can Dedifferentiate to Replace Lost Lgr5+ Intestinal Stem Cells Revealing that Many Different Progenitor Populations Can Regain Stemness. Stem Cell Investig. 3, 61. doi:10. 21037/sci.2016.09.15

Katoh, Y., and Katoh, M. (2006). Hedgehog Signaling Pathway and Gastrointestinal Stem Cell Signaling Network (Review). Int. J. Mol. Med. 18, 1019-1023. doi:10.3892/ijmm.17.1.171

Kim, J.-H., Thimmulappa, R. K., Kumar, V., Cui, W., Kumar, S., Kombairaju, P., et al. (2014). NRF2-mediated Notch Pathway Activation Enhances Hematopoietic Reconstitution Following Myelosuppressive Radiation. J. Clin. Invest. 124, 730-741. doi:10.1172/jci70812

Kim, K., Damoiseaux, R., Norris, A. J., Rivina, L., Bradley, K., Jung, M. E., et al. (2011). High Throughput Screening of Small Molecule Libraries for Modifiers of Radiation Responses. Int. J. Radiat. Biol. 87, 839-845. doi:10.3109/09553002. 2011.560994

Kim, K., and McBride, W. H. (2010). Modifying Radiation Damage. Curr. Drug Targets. 11, 1352-1365. doi:10.2174/1389450111009011352
Kim, K., Pollard, J. M., Norris, A. J., McDonald, J. T., Sun, Y., Micewicz, E., et al. (2009). High-Throughput Screening Identifies Two Classes of Antibiotics as Radioprotectors: Tetracyclines and Fluoroquinolones. Clin. Cancer Res. 15, 7238-7245. doi:10.1158/1078-0432.ccr-09-1964

Lant, B., and Derry, W. B. (2014). High-Throughput RNAi Screening for Germline Apoptosis Genes in Caenorhabditis elegans. Cold Spring Harb Protoc. 2014, 428-434. doi:10.1101/pdb.prot080234

Laval, S., Dayoub, W., Favre-Reguillon, A., Berthod, M., Demonchaux, P., Mignani, G., et al. (2009). A Mild and Efficient Method for the Reduction of Nitriles. Tetrahedron Lett. 50, 7005-7007. doi:10.1016/j.tetlet.2009.09.164

Ledney, G. D., Madonna, G. S., Moore, M. M., Elliott, T. B., and Brook, I. (1992). Synthetic Trehalose Dicorynomycolate and Antimicrobials Increase Survival from Sepsis in Mice Immunocompromised by Radiation and Trauma. J. Med. 23, 253-264.

Li, C., Lu, L., Zhang, J., Huang, S., Xing, Y., Zhao, M., et al. (2015). Granulocyte Colony-Stimulating Factor Exacerbates Hematopoietic Stem Cell Injury after Irradiation. Cell Biosci. 5, 65. doi:10.1186/s13578-015-0057-3

Liu, T., Zhu, L., Zhang, Z., Huang, H., Zhang, Z., and Jiang, L. (2017). Protective Role of Trehalose during Radiation and Heavy Metal Stress in Aureobasidium Subglaciale F134. Sci. Rep. 7, 17586. doi:10.1038/s41598-017-15489-0

Luis, T. C., Naber, B. A. E., Roozen, P. P. C., Brugman, M. H., de Haas, E. F. E., Ghazvini, M., et al. (2011). Canonical wnt Signaling Regulates Hematopoiesis in a Dosage-dependent Fashion. Cell Stem Cell 9, 345-356. doi:10.1016/j.stem. 2011.07.017

Ma, J., Wang, R., Fang, X., and Sun, Z. (2012). $\beta$-Catenin/TCF-1 Pathway in T Cell Development and Differentiation. J. Neuroimmune Pharmacol. 7, 750-762. doi:10.1007/s11481-012-9367-y

Madsen, K., Knudsen, L. B., Agersoe, H., Nielsen, P. F., Thøgersen, H., Wilken, M., et al. (2007). Structure-Activity and Protraction Relationship of Long-Acting Glucagon-like Peptide-1 Derivatives: Importance of Fatty Acid Length, Polarity, and Bulkiness. J. Med. Chem. 50, 6126-6132. doi:10.1021/jm070861j

Maelfait, J., Liverpool, L., and Rehwinkel, J. (2020). Nucleic Acid Sensors and Programmed Cell Death. J. Mol. Biol. 432, 552-568. doi:10.1016/j.jmb.2019. 11.016

Mason, K. A., Withers, H. R., McBride, W. H., Davis, C. A., and Smathers, J. B. (1989). Comparison of the Gastrointestinal Syndrome After Total-Body or Total-Abdominal Irradiation. Radiat. Res. 117, 480-488. doi:10.2307/3577353 Matsuzawa, T. (1965). Survival Time in Germfree Mice After Lethal Whole Body X-Irradiation. Tohoku J. Exp. Med. 85, 257-263. doi:10.1620/tjem.85.257

McBride, W. H., Thacker, J. D., Comora, S., Economou, J., Hogge, D., and Dougherty, G. J. (1992). IL-7 Gene Infection of a Murine Fibrosarcoma Fsa Enhances Tumor Immunity. Proc. Am. Assoc. Cancer Res. Annu. Meet. 33, 334 . .

McBride, W. H., and Schaue, D. (2020). Radiation-induced Tissue Damage and Response. J. Pathol. 250, 647-655. doi:10.1002/path.5389

Medhora, M., Gao, F., Fish, B. L., Jacobs, E. R., Moulder, J. E., and Szabo, A. (2012). Dose-modifying Factor for Captopril for Mitigation of Radiation Injury to Normal Lung. J. Radiat. Res. 53, 633-640. doi:10.1093/jrr/rrs004

Micewicz, E. D., Kim, K., Iwamoto, K. S., Ratikan, J. A., Cheng, G., Boxx, G. M., et al. (2017). 4-(Nitrophenylsulfonyl)piperazines Mitigate Radiation Damage to Multiple Tissues. PLoS One 12, e0181577. doi:10.1371/journal.pone.0181577

Micewicz, E. D., Iwamoto, K. S., Ratikan, J. A., Nguyen, C., Xie, M. W., Cheng, G., et al. (2019). The Aftermath of Surviving Acute Radiation Hematopoietic Syndrome and its Mitigation. Radiat. Res. 191, 323-334. doi:10.1667/rr15231.1

Moparthi, L., and Koch, S. (2019). Wnt Signaling in Intestinal Inflammation. Differentiation 108, 24-32. doi:10.1016/j.diff.2019.01.002

Murray, D., and McBride, W. H. (1996). Radioprotective Agents. Kirk-Othmer Encyclopedia of Chemical Technology. 4th Edn. Chichester, United Kingdom: John Wiley \& Sons, Inc.

Na Nakorn, T., Traver, D., Weissman, I. L., and Akashi, K. (2002). MyeloerythroidRestricted Progenitors are Sufficient to Confer Radioprotection and Provide the Majority of Day 8 CFU-S. J. Clin. Invest. 109, 1579-1585. doi:10.1172/jci0215272

Omenetti, A., and Diehl, A. M. (2008). The Adventures of Sonic Hedgehog in Development and Repair. II. Sonic Hedgehog and Liver Development, Inflammation, and Cancer. Am. J. Physiol. Gastrointest. Liver Physiol. 294, G595-G598. doi:10.1152/ajpgi.00543.2007

Ouspenskaia, T., Matos, I., Mertz, A. F., Fiore, V. F., and Fuchs, E. (2016). WNTSHH Antagonism Specifies and Expands Stem Cells Prior to Niche Formation. Cell 164, 156-169. doi:10.1016/j.cell.2015.11.058 
Paithankar, J. G., Raghu, S. V., and Patil, R. K. (2018). Concomitant Changes in Radiation Resistance and Trehalose Levels during Life Stages of Drosophila melanogaster Suggest Radio-Protective Function of Trehalose. Int. J. Radiat. Biol. 94, 576-589. doi:10.1080/09553002.2018.1460499

Perlovich, G. L., Kazachenko, V. P., Strakhova, N. N., and Raevsky, O. A. (2014). Impact of Sulfonamide Structure on Solubility and Transfer Processes in Biologically Relevant Solvents. J. Chem. Eng. Data 59, 4217-4226. doi:10. 1021/je500918t

Pitter, K. L., Tamagno, I., Feng, X., Ghosal, K., Amankulor, N., Holland, E. C., et al. (2014). The SHH/Gli Pathway is Reactivated in Reactive Glia and Drives Proliferation in Response to Neurodegeneration-Induced Lesions. Glia 62, 1595-1607. doi:10.1002/glia.22702

Quastler, H. (1945a). Studies on Roentgen Death in Mice. Am. J. Roentgenol Radium Ther. 54, 449-461.

Quastler, H. (1945b). Studies on Roentgen Death in Mice; Body Weight and Sensitivity. Am. J. Roentgenol Radium Ther. 54, 457-461.

Quastler, H. (1945c). Studies on Roentgen Death in Mice; Survival Time and Dosage. Am. J. Roentgenol Radium Ther. 54, 449-456.

Razumilava, N., Gumucio, D. L., Samuelson, L. C., Shah, Y. M., Nusrat, A., and Merchant, J. L. (2018). Indian Hedgehog Suppresses Intestinal Inflammation. Cell. Mol. Gastroenterol. Hepatol. 5, 63-64. doi:10.1016/j.jcmgh.2017.10.003

Sacher, G. A., and Grahn, D. (1964). Survival of Mice under Duration-of-Life Exposure to Gamma Rays. I. The Dosage-Survival Relation and the Lethality Function. J. Natl. Cancer Inst. 32, 277-321.

Saha, S., Aranda, E., Hayakawa, Y., Bhanja, P., Atay, S., Brodin, N. P., et al. (2016). Macrophage-Derived Extracellular Vesicle-Packaged WNTs Rescue Intestinal Stem Cells and Enhance Survival after Radiation Injury. Nat. Commun. 7, 13096. doi:10.1038/ncomms13096

Schaue, D., Xie, M. W., Ratikan, J. A., and McBride, W. H. (2012). Regulatory T Cells in Radiotherapeutic Responses. Front. Oncol. 2, 90. doi:10.3389/fonc. 2012.00090

Schaue, D., and McBride, W. H. (2019). Are Animal Models a Necessity for Acute Radiation Syndrome Drug Discovery? Expert Opin. Drug Discov. 14, 511-515. doi:10.1080/17460441.2019.1591364

Schaue, D., and McBride, W. H. (2010). Links between Innate Immunity and Normal Tissue Radiobiology. Radiat. Res. 173, 406-417. doi:10.1667/rr1931.1

Schaue, D., Micewicz, E. D., Ratikan, J. A., Xie, M. W., Cheng, G., and McBride, W. H. (2015). Radiation and Inflammation. Semin. Radiat. Oncol. 25, 4-10. doi:10. 1016/j.semradonc.2014.07.007

Shen, X., Peng, Y., and Li, H. (2017). The Injury-Related Activation of Hedgehog Signaling Pathway Modulates the Repair-Associated Inflammation in Liver Fibrosis. Front. Immunol. 8, 1450. doi:10.3389/fimmu.2017.01450

Singh, B. N., Weaver, C. V., Garry, M. G., and Garry, D. J. (2018). Hedgehog and Wnt Signaling Pathways Regulate Tail Regeneration. Stem Cells Dev. 27, 1426-1437. doi:10.1089/scd.2018.0049

Singh, V. K., and Seed, T. M. (2020). Pharmacological Management of Ionizing Radiation Injuries: Current and Prospective Agents and Targeted Organ Systems. Expert Opin. Pharmacother. 21, 317-337. doi:10.1080/14656566. 2019.1702968

Steinman, J., Epperly, M., Hou, W., Willis, J., Wang, H., Fisher, R., et al. (2018). Improved Total-Body Irradiation Survival by Delivery of Two Radiation Mitigators that Target Distinct Cell Death Pathways. Radiat. Res. 189, 68-83. doi:10.1667/RR14787.1

Supuran, C. (2017). Special Issue: Sulfonamides. Molecules 22, 1642. doi:10.3390/ molecules 22101642
Tetteh, P. W., Farin, H. F., and Clevers, H. (2015). Plasticity Within Stem Cell Hierarchies in Mammalian Epithelia. Trends Cell Biol. 25, 100-108. doi:10. 1016/j.tcb.2014.09.003

Tian, H., Biehs, B., Warming, S., Leong, K. G., Rangell, L., Klein, O. D., et al. (2011). A Reserve Stem Cell Population in Small Intestine Renders Lgr5-Positive Cells Dispensable. Nature 478, 255-259. doi:10.1038/nature10408

van Os, R., Robinson, S., Sheridan, T., and Mauch, P. M. (2000). GranulocyteColony Stimulating Factor Impedes Recovery from Damage Caused by Cytotoxic Agents through Increased Differentiation at the Expense of SelfRenewal. Stem Cells 18, 120-127. doi:10.1634/stemcells.18-2-120

Wabik, A., and Jones, P. H. (2015). Switching Roles: the Functional Plasticity of Adult Tissue Stem Cells. EMBO J. 34, 1164-1179. doi:10.15252/embj.201490386

Webb, K. M., and DiRuggiero, J. (2012). Role of Mn2+ and Compatible Solutes in the Radiation Resistance of Thermophilic Bacteria and Archaea. Archaea 2012, 845756. doi:10.1155/2012/845756

Williams, G. T., Smith, C. A., Spooncer, E., Dexter, T. M., and Taylor, D. R. (1990). Haemopoietic Colony Stimulating Factors Promote Cell Survival by Suppressing Apoptosis. Nature 343, 76-79. doi:10.1038/343076a0

Williams, J. P., and McBride, W. H. (2011). After the Bomb Drops: A New Look at Radiation-Induced Multiple Organ Dysfunction Syndrome (MODS). Int. J. Radiat. Biol. 87, 851-868. doi:10.3109/09553002.2011.560996

Wilson, B. R. (1963). Survival Studies of Whole-Body X-Irradiated Germfree (Axenic) Mice. Radiat. Res. 20, 477-483. doi:10.2307/3571378

Yamaguchi, M., Suzuki, M., Funaba, M., Chiba, A., and Kashiwakura, I. (2020). Mitigative Efficacy of the Clinical Dosage Administration of Granulocyte Colony-Stimulating Factor and Romiplostim in Mice with Severe Acute Radiation Syndrome. Stem Cell Res. Ther. 11, 339. doi:10.1186/s13287-02001861-x

Yan, K. S., Chia, L. A., Li, X., Ootani, A., Su, J., Lee, J. Y., et al. (2012). The Intestinal Stem Cell Markers Bmil and Lgr5 Identify Two Functionally Distinct Populations. Proc. Natl. Acad. Sci. U.S.A. 109, 466-471. doi:10.1073/pnas. 1118857109

Yoshinaga, K., Yoshioka, H., Kurosaki, H., Hirasawa, M., Uritani, M., and Hasegawa, K. (1997). Protection by Trehalose of DNA from Radiation Damage. Biosci. Biotechnol. Biochem. 61, 160-161. doi:10.1271/bbb.61.160

Zhou, Y., Jin, J., Feng, M., and Zhu, D. (2019). Wnt Signaling in Inflammation in Tissue Repair and Regeneration. Curr. Protein Pept. Sci. 20, 829-843. doi:10. 2174/1389203720666190507094441

Conflict of Interest: Author GD was employed by the company Shanghai Jiyu Pharmaceutical Technology Co., Ltd. Of note, the drugs 057, 52A1, and NPSP512 have been licenced by BCN of which the co-author AN is a director.

The remaining authors declare that the research was conducted in the absence of any commercial or financial relationships that could be construed as a potential conflict of interest.

Copyright (C) 2021 Micewicz, Damoiseaux, Deng, Gomez, Iwamoto, Jung, Nguyen, Norris, Ratikan, Ruchala, Sayre, Schaue, Whitelegge and McBride. This is an openaccess article distributed under the terms of the Creative Commons Attribution License (CC BY). The use, distribution or reproduction in other forums is permitted, provided the original author(s) and the copyright owner(s) are credited and that the original publication in this journal is cited, in accordance with accepted academic practice. No use, distribution or reproduction is permitted which does not comply with these terms. 